\title{
Analysis of Nanjing River Treatment Based on PPP Model
}

\author{
Howard HaoXuan Wang ${ }^{1}$ and Hongying $\mathrm{Ji}^{\#}$ \\ ${ }^{1}$ UWC High School, Changshu, Jiangsu, China \\ "Advisor
}

$\underline{\text { ABSTRACT }}$

The PPP model is an essential tool to understand how different stakeholders cooperate and their respective roles in river management in Nanjing. This article adopts a qualitative research approach to do research design and uses semistructured interviews to collect data. After analyzing, we find that the government, enterprise, and NGOs work together collaboratively to achieve a win-win situation within the PPP model. Although NGOs are not included in the original PPP model, in our study, we found that in the practice of river management in Nanjing, NGOs served as a bridge, connecting the public and private sectors.

\section{Introduction}

The PPP (Public-Private Partnership) model has spread to many parts of the world and has been indigenized to address different social problems. Both private and public parties use PPPs to satisfy their interests at the end of the deal (Chen, 2013). In practice, the private parties, namely enterprises, are interest-oriented, while the public parties, including the government, are socially minded and seek very cost-efficient means of delivering infrastructure (Suchman et al., 2018). A win-win where the interests of both parties are achieved is relevant to the sustenance of the PPPs. In this paper, we attempt to examine the experience of Nanjing river management. Our purpose is two-fold: 1) to explore the current status of river management in Nanjing, and 2) to look at the cooperation approach between the public sector and private sector.

\section{Review of Literature}

Due to the differences in terms of legal, financial, political, economic, cultural, and industrial backgrounds by countries and organizations, PPP cannot be accurately defined (Zhang et al., 2016). According to Olusola et al. (2012), "PPP is a partnership between public sector organizations and private sector investors and business for the purpose of designing, planning, financing, constructing, providing and/or operating infrastructure, facilities or related services" (p. 214). Pellegrino et al. (2019) defined PPP as a comprehensive tool that governments can use to provide public infrastructure, drawing on the innovation and expertise of the private sector and often private financing.

With the consideration and needs of both sectors in different regions increasing, PPPs have been attached to much importance (Kumaraswamy et al., 2007). According to Buso and Stenger (2018), "PPPs may allow the public regulator to be more actively involved in a bargaining process with the private agent for decisions concerning the level of investment and the cost sharing scheme" (p. 490). The capital stock of PPP projects have stably rosed over time and now accounts for about 2 percent of GDP in developed countries and 7 percent in developing countries (IMF 2017: $5)$. 
Since there remains to this day no one single agreed-upon definition of PPP (Hodge and Greve et al., 2007), PPP has come to be used as an umbrella term describing collaborative relationships between public and private actors for the achievement of common goals (Singh and Prakash et al., 2010).

China is trying to bring different stakeholders together in the river management group through different policy regulations. Through the previous attempts of the 11th and 12th Five-Year Plans, the government promulgated the "Action Plan for Prevention and Control of Water Pollution" in 2015, which emphasizes the role of the market in river management, and also hopes that the public can play a monitoring role to create a better water environment.

Therefore, employing the PPP model to analyze the current situation of river management in Nanjing is a concrete way to present the cooperation between the public sector and the private sector. Meanwhile, it is also an exploratory study of the current river management model in Nanjing.

\section{Methods}

In this study, we primarily used semi-structured interviews as a data collection method. We purposefully sampled six stakeholders in the PPP model, one government staff, two NGO staff, the directors of two wastewater treatment plants and a private river manager and conducted in-depth interviews. This study followed standard research ethics considerations and practices, such as informed consent, anonymity and safety of data storage, detachment of research from course requirements and evaluative components. Interview data were recorded and coded before being thematically analyzed. To begin with, we recoded 10 different items, and after analyzing them, they were arranged into 3 conceptual factors to demonstrate how public sectors and private sectors can work together to solve the challenges of river management in a cooperative way.

\section{Results}

Government and business represent the Public and private sectors, respectively, and they also play different roles in river management, while NGOs provide essential platforms for all sides.

The Government: The One in Charge and Coordinator

Governors of Nanjing consider and speak up for the Public. They made regulations to businesses, appealed to citizens to participate in public issues, and set goals for themselves. They are leading the issue's solving and are definitely in charge of it. The government published the "3-3-3 movement outlines" to reduce the wastewater disposal pressure. The "3-3-3 movement" includes three eliminations, three rectifies, and three improvements. The three eliminations are: to eliminate all the black and odorous rivers and lakes; to eliminate all areas without wastewater networks; and eliminate wastewater discharging into the rivers directly.

Moreover, the three rectifies are: rectify illegal drainage from enterprises and factories, shops and courtyards. Ultimately, the three improvements are: to improve wastewater disposal efficiency, improve the quality of the new wastewater network, and improve the skills at repairing wastewater networks. With the announcement of the "3-3-3 movement", the water quality has been gradually getting better. The "3-3-3 movement" has rectified 24 rivers and created a harmonious environment.

Why did the government transform into the coordinator? Because the government has another goal: to conserve this harmonious environment and retain it. However, the government cannot accomplish river management alone; it needs enterprises and individuals to accomplish it together. The government has shown relatively different attitudes towards enterprises and citizens. Towards the enterprises, they have published several purposeful regulations. Recently, there has been a policy that all enterprises in charge of wastewater disposal need specific certificates. The certificate is compulsory. As can be seen, it would be a challenge to get that certificate. This certificate would be valid only for five years. Five years later, they need to reapply for the certificate to ensure legitimacy. If not, they might receive a penalty. 
However, the government may only appeal to the citizens to participate in environmental protection events if not insist. Nonetheless, the citizens did play an essential role in river treatment. Every citizen could be a monitor, supervising the status of river management. If they find any problems, they can report them to the government. Not only that, with the notice boards along with the lake set by the government that includes the detailed information of the lake and the reports hotlines, they can call the hotlines when they spot some problems occurring. The government personnel will solve the problem immediately.

\section{Enterprise: Main Implementer}

Why are enterprises critical members of wastewater management? Because they are the ones who implement wastewater disposal. Not the government, not the citizens; they perform river treatment policy like a natural executive body. How could the enterprises affect wastewater disposal? Mainly through 2 approaches. The first approach is through technology updating. A2/O is a typical improvement. Before the advent of A2/O, factories used SBR for wastewater purification, with only one reaction pond with different functions at different periods. One pond goes through pool homogenization, primary settling, biodegradation, secondary settling, and 4 stages. All functions play an essential role. Currently, the A2/O technique was invented and widely used due to its high efficiency. A2/O is anaerobic, anoxia, and aerobic which has a particular effect on removing nitrogen. According to the government policy, all the wastewater disposal must use A2/O in the Nanjing Gaoke wastewater treatment plant.

The second approach is through educating. The enterprises, namely, the wastewater disposal factory, also have been involved in public education. The Gaoke wastewater treatment plant manager mentioned one of his "funny" stories: "I had told my son that I work at a wastewater disposal factory, my son told his friends that his father is a sewer worker. My son used to think his father as a plumber who repairs the stench sewage!" The citizens are not familiar with "wastewater disposal" and have this type of stereotype. In order to change that, the Nanjing Gaoke wastewater treatment plant started opening towards many local citizens, especially school students, and encouraging people to learn more about wastewater management. Now, in Nanjing, four batches of enterprises related to environmental protection are gradually opening to the Public. Tiebei wastewater treatment plant and Gaoke wastewater treatment plant factory are two examples of these types of enterprises.

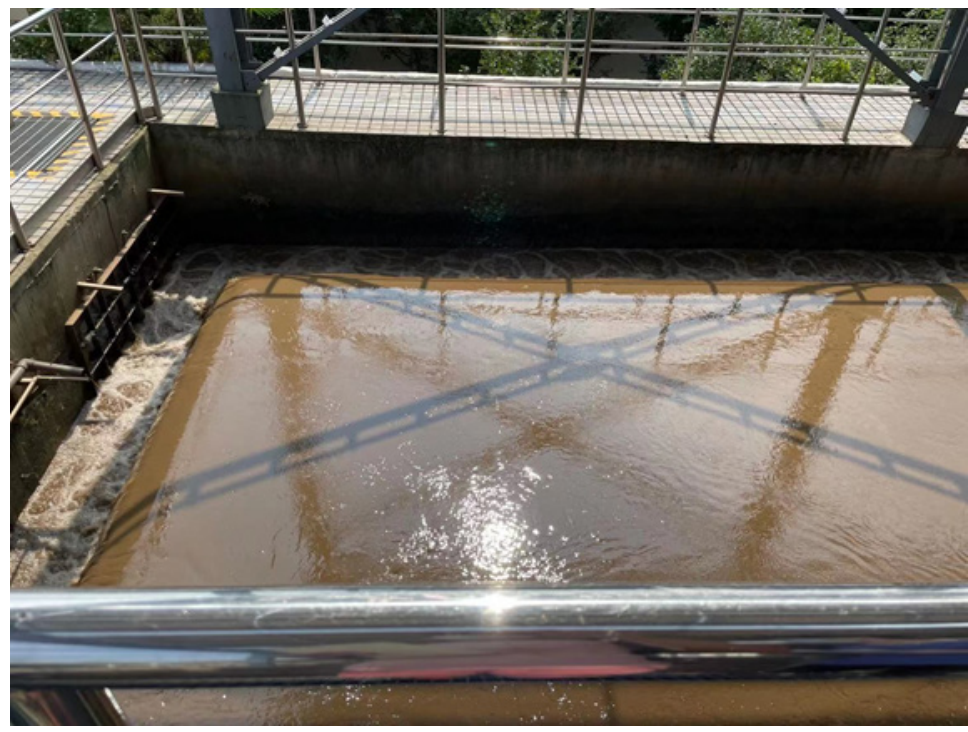

Figure1: A2/O process pool 


\section{NGOs: Platform Builder}

Non-governmental organizations (NGOs) refer to non-profit social organizations with formal organizational forms and belonging to the non-governmental system. They have a certain degree of autonomy, volunteerism, public welfare or mutual benefit. China's Ministry of Civil Affairs divides non-governmental organizations into social organizations and private non enterprise units. NGO stands and proposes the solutions that will be helpful and brings benefits to the citizens. NGOs usually react simultaneously to citizens' wishes and bring the government, related enterprises, and citizens together in solving social problems. Green Stone Environmental Protection Center is a non-governmental environmental protection organization based in Jiangsu and committed to solving local environmental problems. In an interview, Center's manager said: "a chemical industrial park in Nantong had a problem with the smell that influences the local citizens. After confirmed, Green Stone got involved instantly. To begin with, we figured out the situation from the local and then had a meeting with the management committee. It worked not before long, and then the smell problem was solved successfully."

In a traditional PPP, there are 2 sectors___ government and enterprises; however, here in Nanjing river treatment, NGOs have been found to participate. NGOs provide a "platform" that allows both sides to understand others' "voice". Someone might be confused: what are the three sides? Three sides represent individuals, governments and enterprises. NGOs combine these three actors to achieve the same goal, by which NGOs build a platform for all sides, including themselves. Sometimes they may have conflicts with others since they have different interests. Although there will be some challenges to achieve the "true balance," they still work hard to benefit all. As the worker said, "If humans and nature could become one unit, we will not need the support from NGO".

\section{Discussion}

Governments, NGOs, enterprises, and individuals cannot operate very well when they only act independently. However, if they combine and cooperate, they can demonstrate a much stronger society. At the start, the government has placed a range of wastewater disposal policies on enterprises, NGOs, and individuals, as the one in charge and a coordinator. Accordingly, different characters responded differently. The enterprises, especially wastewater treatment plants, must follow the wastewater disposal policy completely. Otherwise, they will receive a penalty from the government. NGOs built a platform for communication among various bodies. Even though individuals act differently and cannot judge and decide anything by themselves, they can nearly do everything they want when they cooperate and unite. Under this circumstance, governments, NGOs, enterprises, and individuals formed a well-established PPP model. 


\section{Journal of Student Research}

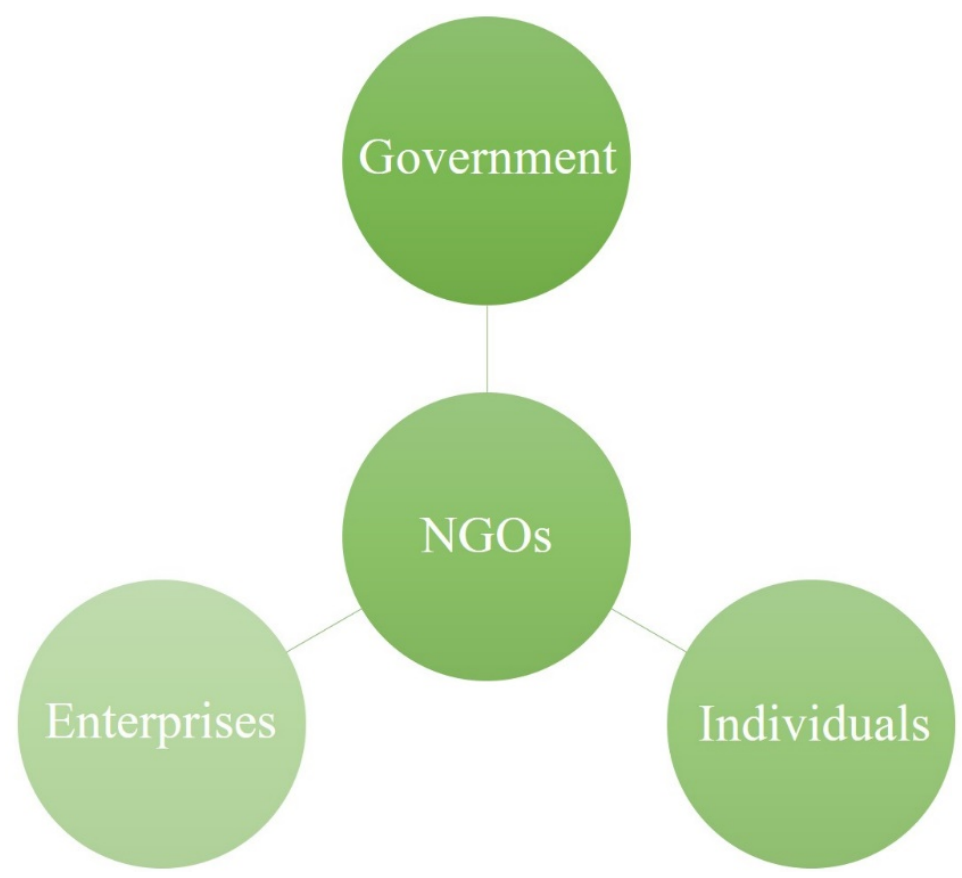

Figure2: New PPP framework employed in Nanjing river management

The government, enterprises, and NGOs do not have equal rights to speak when it comes to river governance, although they need to work together to achieve the goal of combating water pollution and creating a better water environment. In practice, the three stakeholders also play different roles. The government always occupies the central policy-making position. Enterprises can improve the technology of river management through continuous technological innovation to improve the efficiency of river management and reduce the cost of river management. As an essential part of the PPP model, NGOs play their unique role in redistributing social resources and connecting government, enterprises, and individuals. When it comes to the theory of PPP governance, Xiong (2018) identified 21 governance issues in 52 case studies and found that the most critical ones are cooperation, trust, communication, capability, risk allocation and sharing, competition, and transparency. In Nanjing's case, it is the existence of NGOs that provides a platform for different stakeholders to hear each other's voices, promoting cooperation and so on.

In the application of the PPP model, there are also many risks. Rybnicek et al. (2020) revealed that out of the 159 investigated articles, the most often named factors (risks) are contract (59\%), resources (58\%), objectives (45\%), structure (40\%), commitment (39\%), environment (36\%), communication (31\%), and trust (31\%). This also reflects that although PPP is a highly desirable model between public and private partners to share resources, risks, responsibilities and rewards to mutually gain social, economic, or environmental objectives (Kwak et al., 2009). Therefore, if we want to better use the PPP model in the governance of social problems, we have to address the potential risk factors.

\section{Conclusion and Implications}

This study uses qualitative research to explore river management in Nanjing under the PPP model. The study identified new PPP cooperation models with local characteristics used in Nanjing river management. Among them, individuals and non-profit organizations play an increasingly important role in Nanjing's river management. Nanjing's practical experience is significant for exploring solutions for river management in China and other parts of the world. 


\section{Future Research}

We hope that future research can be conducted in the following areas.

1. Conducting more in-depth research on the role played by individuals in river management.

2. Conducting empirical research on river governance models in other regions and investigating whether the PPP model is practiced in different regions.

3. Conducting more research on the risk factors of the PPP model.

\section{Limitations}

There are still some shortcomings in the field investigation and in-depth study of the topic under discussion. For example, this paper does not delve into the role of individuals in wastewater prevention, but the role individuals play in river management should not be underestimated. Hoping future research can focus on this point in depth.

\section{Acknowledgments}

I want to show my deepest gratitude to my supervisor, Nancy, a responsible and patient advisor, who has provided me with valuable guidance in every stage of the writing of this article. I would also like to express my gratitude to the interviewees. It was their sharing that gave me a lot of field research material to complete this article.

\section{References}

Eshun, B.T.B., Chan, A.P.C. and Osei-Kyei, R. (2020), "Conceptualizing a win-win scenario in public-private partnerships: evidence from a systematic literature review", Engineering, Construction and Architectural Management, Vol. ahead-of-print No. ahead-of-print. http://doi.org/10.1108/ECAM-07-2020-0533 Institutional introduction. (2012). Greenstone Environmental Protection Center. http://www.greenstone.org/cn/about/

Jayasena, N. S., Chan, D. W. M., \& Kumaraswamy, M. (2021). A systematic literature review and analysis towards developing PPP models for delivering smart infrastructure. Built Environment Project and Asset Management, 11(1), 121-137. http://doi.org/10.1108/BEPAM-11-2019-0124 Ming.W \& Xijin.J.(2002). Analysis of the development of NGOs in China. Manage the world(08),30-43+154-155. doi:10.19744/j.cnki.11-1235/f.2002.08.006.

Torchia, M., Calabro, A., \& Morner, M. (2015). Public-Private Partnerships in the Health Care Sector: A systematic review of the literature. Public Management Review, 17(2), 236-261. http://doi.org/10.1080/14719037.2013.792380 Petersen, O. H. (2019). Evaluating the Costs, Quality, and Value for Money of Infrastructure Public-Private Partnerships: A Systematic Literature Review. Annals of Public and Cooperative Economics, 90(2), $227-244$. http://doi.org/10.1111/apce.12243

Xiong, W., Chen, B., Wang, H., \& Zhu, D. (2019). Governing public-private partnerships: A systematic review of case study literature. Australian Journal of Public Administration, 78(1), 95-112. http://doi.org/10.1111/14678500.12343

Rybnicek, R., Plakolm, J., \& Baumgartner, L. (2020). Risks in Public-Private Partnerships: A Systematic Literature Review of Risk Factors, Their Impact and Risk Mitigation Strategies. Public Performance \& Management Review, 43(5), 1174-1208. http://doi.org/10.1080/15309576.2020.1741406

Zhuo.L.(2003). Definition and Classification of NGOs in Chin. China Administration(03),25-26.

doi:CNKI:SUN:ZXGL.0.2003-03-007. 